\title{
Liquidity risk contagion in the Interbank Market
}

\begin{abstract}
This paper studies liquidity risk contagion within the interbank market by assessing the long-run relationship of short-term interest rate spreads from January 2002 to December 2015. In particular, we model the interaction between the LIBOR-OIS spread, euro fixed-float OIS swap rate and the threemonth US-German bond spread and discover strong evidence of structural innovations affecting the interbank market. We find that when the short-term interbank market is affected by a liquidity shock, the LIBOR-OIS spread is a leader in moving back to equilibrium, while the euro-dollar currency swap rate and the US-German bond spreads are followers. Moreover, we find long-run cointegrating relationships and bi-directional causality between the spreads. However, structural breaks identified as prospective financial crises affect the long-run relationships and liquidity shocks drive interbank rates and spread fluctuations. Therefore, liquidity shocks propagating within the interbank market can forecast benchmark interest movements, and ultimately this has significant implications for policy-makers and market players alike.
\end{abstract}

Keywords: Contagion, Financial Crises, Interbank Market, Liquidity shocks, Structural breaks

JEL classification: C32, G15

\section{Introduction}

This paper studies liquidity risk contagion within the short-term interbank market in times of financial market turmoil. During the early stages of the financial crisis of 2007-08, liquidity risk observed in one market quickly spilled over to neighbouring markets. Identifying liquidity shocks with destabilising effects on the short-term market well before they propagate and spread is paramount in both crisis management and preventing market downturns. According to economic theory interbank linkages determine how liquidity risk moves from one market to another (Upper and Worms, 2004). 
However, the theory does not explain how economic and financial variables are interconnected and how shocks originating from equilibrium relationships drive liquidity risk spillovers.

Illiquidity contagion between leading financial institutions caused by the 2007-08 credit crisis highlights the importance of identifying causality, equilibrium relationships and structural breaks within the short-term interbank market. If rates and spreads move independently in the long-run, they are said to follow a random walk and rates and spread dynamics are unpredictable. However, if rates and spreads are interconnected and move in a synchronised fashion, we gain crucial insights into the propagation of liquidity shocks within the interbank market. Moreover, looking in depth at the interaction between the money market spreads before and during a financial crisis, one can understand in what way structural breaks affect equilibrium relationships and what are the implications for the smooth functioning of the interbank market in terms of liquidity crisis prevention and forecasting.

There are several motivations for conducting our investigation. First, we intend to determine whether the LIBOR-OIS spread, the three-month US-German bond spread and the euro fixed-float OIS swap are interdependent and whether some of the variables cause changes in others. If that is the case, then one can predict movements in benchmark short-term interbank spreads and rates, anticipate unfavourable financial events unfolding and prevent them if counteracting policy interventions are introduced. Second, if liquidity shocks affect the short-term interbank market, one is able to trace the forecast error variance of the variables of interest to reveal what exactly drives movements in benchmark spreads and rates. Third, if long-run equilibrium relationships exist among the time series, this would reveal that significant (liquidity) shocks may translate into extreme financial events as witnessed during the financial crisis of 2007-08. Last, the uncertainty surrounding the progression of interbank spread variability is believed to be exogenous. Hence, it is assumed that interest rate variability is not conditional on shocks evolving from within the rates under investigation, nor on the actions of financial institutions or other market players. When the interbank market is not in turmoil, this view is rather benign. However, in crisis periods when information and beliefs are more likely to become homogenous, related interest rates behave in a similar fashion. In such cases, liquidity shocks are amplified from within the system as part of some self-fulfilling forecasts or endogenous responses (Daníelsson, 2011). Thus, our study shows that endogenous structural innovations within established equilibrium relationships 
explain the forecast error variance of the other time series.

Since 2008, the literature has focused on assessing liquidity risk and trading behaviour during financial distress, whereas the empirical literature on contagion is surprisingly limited considering the importance of the subject. Besides, the majority of the empirical financial crisis literature (Upper and Worms (2004); Upper (2011); Mistrulli (2011); Gorton and Metrick (2012), among others) disregard the important characteristics of short-term money market series, such as stationarity, normality and structural changes in the constant term, mean and variance. Whereas Upper (2011) highlights the importance of assessing contagion in order to maintain the smooth functioning and safeguard the stability of the financial system, we aim to advance the literature and reveal important dynamics of liquidity risk contagion within the interbank market.

Our study assesses the long-run behaviour of short-term interest rates and spreads in times of financial turmoil. Geographically, we concentrate on the European and US interbank market providing a comprehensive analysis of the behaviour of leading interbank indicators. Prior to establishing the longrun equilibrium relationships, interdependencies and causality are revealed by following how interbank spreads evolve over time. Vector Autoregression (VAR) identifies whether lagged values of covariates have any effect on each other. The Impulse Response Function (IRF) is used to trace shocks to the forecast error variance. The structural VAR coefficients and Cholesky elements provide efficient parameter estimates revealing a strong evidence of structural innovations affecting the interbank market. ${ }^{1}$ Moreover, we find long-run cointegrating relationships and bi-directional causality between the spreads. However, structural breaks identified as prospective financial crises affect the long-run relationships and liquidity shocks drive the interbank-rate and spread fluctuations.

Our investigation contributes to the literature in several ways. The spreads that are used to construct liquidity measures in earlier analyses omitted the fact that these time series are not stationary in their levels, and therefore are integrated of order one $(\mathrm{I}(1))$. Once the series are $\mathrm{I}(1)$, generally they are also cointegrated. Consequently, it can be argued that previous

\footnotetext{
${ }^{1}$ Also called Cholesky factorisation, the method was developed by André-Louis Cholesky to decompose the correlation matrix into parameters or correlated values. The method was introduced in the business cycle analysis literature by Sims (1980).
} 
analyses' results are questionable due to the use of inadequate econometric tools in assessing liquidity risk and contagion in general. The interval January 2002 to December 2015 covers a longer time period, and not only the period surrounding the latest financial crisis as the majority of studies consider. We show that if structural shocks affect the interbank market, the LIBOR-OIS spread is first, whereas the euro fixed-float OIS swap and the US-German bond spread are followers in adjusting back into equilibrium. At the same time, our analysis projects the magnitude and effects of liquidity shocks on other spreads and interest rates. Last, our study reveals structural changes and their permanent effect in the identified long-run and short-run equilibrium relationships.

The remainder of the paper is organised as follows. Section 2 provides a literature review concerning liquidity risk and contagion. Section 3 presents the data and methodology. Empirical results are reported in Section 4, while Section 5 concludes.

\section{Literature review}

Both the academic literature and financial industry acknowledge that the dynamics of financial crises are fuelled by the propagation of liquidity shocks and subsequent contagion to neighbouring markets and regions. The financial crisis of 2007-08 highlights the importance of market contagion and its association to the structure of connections among financial institutions and their funding maturity. Market failures are the result of propagation of liquidity shocks across financial markets, whereas contagion is seen as the most important aspect of market breakdowns. When a crisis develops, only some institutions or a certain section of the economy is affected, however shocks rapidly propagate to the rest of the financial sector and eventually damage the wider economy. A small liquidity shock in the money market has the potential for a self-fulfilling anticipation of a crisis.

The following sections summarise the literature which focuses on liquidity risk, financial crises and domino effects in the short-term interbank market. We first discuss the theoretical literature which centres on the intermediation process in the presence of frictions (imperfect competition, for example), constraints (funding, for example), information asymmetry and shocks which affect the price formation, decision and behaviour of agents. Second, a summary of the empirical literature is presented where we identify two strands of literature: one looks at financial crises and the propagation of shocks from a 
market microstructure view-point, and the other decomposes the dynamics of contagion into liquidity elements. Last, we discuss LIBOR manipulation and its likely effect on the magnitude of the recent credit crisis.

\subsection{Theoretical models of contagion and financial crises}

The theoretical literature assumes that the system overall is either dynamic or static, and the intermediation process is modelled as an equilibrium process. Overall, the focus of these analyses is on how trade and financial sector links affect the dynamics of contagion in the international bank trade, lending and hedging context. According to Brunnermeier and Oehmke (2012), there are two well defined stages that play a significant role in the development of financial crises. The first one is the run-up stage in which bubbles and imbalances develop. The second stage is the crisis stage in which the risk accrued in the previous stage materialises. The authors emphasise the importance of an amplification mechanism (in the form of a self-fulfilling loop) in the development of the crisis. There are two channels which aid the feedback mechanism. The direct channel is initiated by direct business relationships (interconnectedness of markets, for example), whereas the indirect channel is induced by contagion (such as bank runs or domino effects, for example), or externalities caused by endogenous reactions of market players. To understand the process of contagion, Allen and Gale (2000) focus on a single channel contagion model of liquidity preference, which provides different outcomes depending on whether the market is complete or not. The aim is to understand how cross-holding of deposits in different segments and regions of the banking system actually govern the dynamics of spillovers. In contrast, He and Krishnamurthy (2011) expand their setting to an infinite-horizon while modelling intermediation relationships within the financial system in the presence of shocks. Allen et al. (2009) identify two approaches of dealing with contagion. According to the first approach, Nier et al. (2007), Eisenberg and Noe (2001) and Gai and Kapadia (2010) among others, evaluate systemic risk by analysing direct interbank linkages. These investigations use networks to simulate and assess the effects of shocks to the financial system. Upper and Worms (2004), Furfine (2003) and Mistrulli (2011) among others, apply balance sheet data to assess interbank contagion. For the second approach, Cifuentes et al. (2005) study indirect balance-sheet linkages within the banking system. Shin (2008) develops a theoretical lattice based market microstructure framework which integrates responses from asset price variations and contagion effects among market participants. Kodres and Pritsker 
(2002) note that global diversification due to internationally traded assets (which often share a high correlation) can be channels of cross-regional contagion. Allen et al. (2010) develop a two-period network model to assess how banks which interact with each other react to a shock (bad news, for example), and find that there is a higher probability for debt to be rolled over or being defaulted in an unclustered network than in a clustered one. An important implication is that systemic risk - as a result of contagion - is influenced by the structure of financial networks.

\subsection{Empirical models of contagion and financial crises}

According to economic theory, the risk of contagion is determined by the way financial institutions are linked with each other, thus financial contagion can be modelled as an equilibrium phenomenon (Allen and Gale, 2000; Freixas et al., 2000; Allen et al., 2010; Makarov and Plantin, 2013). Kaminsky and Reinhart (2000) analyse whether the dynamics of contagion are explained by market fundamentals or herding behaviour, and find that contagion is regional rather than global and that one country experiencing financial distress cannot forecast a crisis elsewhere. This is in sharp contrast to the findings of Eichengreen et al. (1996), who believe that currency crisis spillovers are prevalent primarily between countries which are associated via commercial trade links. Moreover, due to the complexity of regional contagion, it is hard to distinguish whether trade links or financial interconnectedness spreads crises from one region to the other. ${ }^{2}$

Some argue that empirical market microstructure provides a foundation for investigating price development and informational relationships in financial markets, which is paramount in describing and understanding financial crises. Daníelsson and Saltoğlu (2003) investigate the short-lived liquidity crisis of December 2000 which struck the Turkish overnight market and show that an institutional level order flow model provides an insight and detailed explanation of decision making in an elaborate way. Hartmann et al. (2001) investigate the microstructure of the overnight Euro money market, specifically looking at monetary policy changes and their effect on intra-day trading patterns. The authors prove that monetary policy changes are mirrored in the widening of spreads, and increased volatility is the result of noisy market

\footnotetext{
${ }^{2}$ Kaminsky and Reinhart (2000) argue that due to the fact that trade is more intraregional rather than inter-regional, financial contagion is contained within a (larger) region and rarely becomes global.
} 
behaviour. Hui et al. (2011) claim that the spillover of the crisis from the US to the European market was moderate between the period mid-2007 to mid2008, and funding liquidity risk played a major part in the development of the global financial crisis. However, during the crisis of 2007-08, the authors find considerable deviations from covered interest rate parity and argue that the widening of the LIBOR-OIS spread mainly reflects funding liquidity risk in the interbank market, and subsequently it can be used to measure funding liquidity conditions. This view is supported by McAndrews et al. (2008) who claim that the spread undeniably contains a significant and time-varying funding liquidity element. Moreover, the LIBOR-OIS spread incorporates counterparty-risk premia, which originates from the counterparty's inability to pay back an interbank loan.

Baba et al. (2008) analyse the crisis spillover to the foreign exchange (FX) and long-term cross currency basis swap markets for the period July 2007 to January 2008. The authors argue that the departure from interest rate parity conditions is due to non-US financial institutions' use of the swap markets to survive US dollar deficiencies they encountered during the crisis. Gorton and Metrick (2012) trace the spillover of the credit crunch by investigating the causes of repo haircuts to find that fluctuations in the interbank LIBOR-OIS spread were correlated with increases in the non-subprime securitised assets and associated derivatives spreads. Other analyses argue that the LIBOROIS spread encompasses credit and liquidity risk premia (McAndrews et al., 2008; Michaud and Upper, 2008; Sengupta and Tam, 2008; Hui et al., 2011). Schwarz (2014) finds that during the first half of the credit crisis of 2007-08, more than $60 \%$ of widening of both the one and three-month Euro LIBOROIS spreads and the Eurozone sovereign debt spreads can be accredited to market liquidity effects. ${ }^{3}$ Frank et al. (2008) test the diffusion of liquidity shocks across US financial markets and find that there was a significant connection between markets and funding liquidity pressure which reached its peak right before the global crisis hit. In times of equilibrium, market illiquidity shocks are fundamentally short-lived, as these give prospects for traders to gain profits and subsequently enhance liquidity and the price discovery process. Contrarily however, in times of distress, systemic risk is

\footnotetext{
${ }^{3}$ Widening risk spreads can be explained by greater compensation claimed by riskaverse investors in case of default. Alternatively, it can be described as a compensation for investors holding less liquid securities.
} 
being created by liquidity shocks which intensify and spread across financial markets. Zhou and He (2012) propose a new contagion-MGARCH model by introducing a new contagion equation which can capture the clustering feature of the risk contagion process. Chau and Deesomsak (2014) develop a financial stress spillover index with time-varying components to trace the source of systemic risk in the US equity, debt, banking, and Forex markets. On the other hand, Smimou and Khallouli (2016) focus on the Eurozone and UK equity market while tracing liquidity risk spillover during the global financial crisis.

The study of contagion has important implications for bank regulations and the development of safety nets when confronting liquidity shocks. Guo et al. (2011) assess the magnitude of economic shocks at aggregate level, and their ensuing contagion between the stock market, real estate, credit default swap (CDS) and energy market during the global financial crisis. The authors argue that regime switches are more frequent at the start of the crisis, and that the stock market and oil price shocks induce the fluctuations observed in the CDS and stock markets in general. Upper and Worms (2004) and Mistrulli (2011) analyse balance sheet information of banks to approximate a matrix of bilateral credit links and assess whether the collapse of a bank can lead to contagion. The focus of these studies is on the spillover effect caused by interbank linkages in the presence or absence of safety nets. However the main limitation of such arguments is that these studies solely look at domestic banks and therefore cross-border channels for spillover are not assessed. Upper (2011) evaluates methodologies based on simulation techniques, yet these analyses do not contribute to assessing bank policies, nor can they be applied to perform stress testing in the banking sector.

\subsection{The LIBOR manipulation and its likely effect on the magnitude of fi- nancial crisis of 2007-08}

The reliability of the US LIBOR rate came under fire in June 2012 when Barclays Bank, UBS, RBS, and Rabobank allegedly under-reported their borrowing costs (Hou and Skeie, 2014). This raises questions over the stability of the financial system, robustness and effectiveness of reference rates, and credibility of financial regulators (Gyntelberg and Wooldridge, 2008). Bank losses during 2007 compelled banks to revise their liquidity needs and prompted the British Bankers' Association to raise monitoring on LIBOR setting (Mackenzie and Tett, 2008). It is believed that throughout several years, participating banks submitted lower rates in order to conceal funding 
problems, which contrasted true market conditions (Mollenkamp and Whitehouse, 2008; Wiseman, 2008). Distorted LIBOR rates may have an adverse effect on economy-wide financial settings; unreliable rates transfer risk and pricing errors across financial markets, thus generating uncertainty and impairing the power of central banks to mitigate financial distress (BIS, 2013).

The majority of the literature investigates banks' LIBOR quotes. Fouquau and Spieser (2015) looks at LIBOR submission of participating banks and find breaks which are matched to real key events in a three-regime threshold regression model. The results on an agglomerative hierarchical clustering analysis reveal that certain banks grouped in cartels manipulated LIBOR rates. Abrantes-Metz et al. (2012) use screening techniques to identify anticompetitive behaviour among the participating banks, and analyse individual quotes versus CDS rates. In spite of the fact that quotes display unusual patterns, the authors find that Libor rates were not manipulated during the period 2007-2008.

Both academia and industry recognize that the LIBOR manipulation is an issue, however due to the fact that there are no specific details about the extent of the manipulation, or how long it was going on, one cannot control for it or test to reveal whether it impacts on the magnitude of the financial crisis of 2007-08.

Our study complements the empirical literature which focuses on liquidity risk contagion and financial crisis in the interbank market. The majority of analyses assess the effects of shocks through interbank links or decompose financial risk into risk elements, however little is known about the dynamics of structural shocks, i.e. how these move between markets and how quickly interbank spreads affected by liquidity shocks adjust back into equilibrium. The novelty of our analysis is that contagion and propagation of liquidity shocks is assessed by implementing a series of alternative techniques, such as structural VAR (which isolates estimates of individual shock behaviour) and cointegration methods which reveal detailed characteristics of short-term interbank rates and spreads. Moreover, our investigation spans over a longer period of time as opposed to the majority of literature which looks in isolation at specific economic or financial events (such as market crashes).

\section{Methodology and data}

Essentially, our study builds a methodological analysis of leading shortterm rates and spreads to determine causality, linear interdependencies, equi- 
librium relationships and structural changes in the short-term interbank market. We first present the data, then the methods used in our analysis. The ultimate aim is to reveal whether liquidity shocks spill-over within the shortterm interbank market and whether liquidity shocks disturb the established long-run equilibrium relationships.

\subsection{Data}

The data set is constructed with historical closing daily spread between the US LIBOR and overnight indexed swap (OIS) rate (LIBOR-OIS), the daily three-month US-German bond spread (USGer3M) and the daily threemonth euro fixed-float OIS swap rate (EUSWEC). The data covers the period of 1st January 2002 to 31th December 2015, thereby including the pre- and post-crisis period with the possibility of structural breaks in the time series. The reason for using longitudinal and cross-sectional money market interest rates and spreads is that these carry a liquidity component (premia) on term unsecured interbank loans. Moreover, banks are interconnected crossregionally, primarily due to cross-ownership of financial institutions. In turbulent market conditions, all the spreads used in the present study are good indicators of risk premiums as a result of credit, funding-liquidity, default, Forex, and ultimately systemic risk. Moreover, the spreads reflect movements in interest rates of the two significant geographical markets affected by the financial crisis of 2007-08, that is the Eurozone and US market.

The London Interbank Offered Rate (LIBOR) is used as a reference rate in financial contracts all over the world and is the rate at which banks and institutions of similar size agree to lend each other. The rate is paid on unsecured interbank loans of various maturities (up to 12 months). Changes in the LIBOR rate can be attributed primarily to open market operations implemented by central banks in order to re-price short-term loans between banks. Increases in LIBOR rates can be credited to banks calling for greater compensation in case of default risk on their loans. The Overnight Interest Swap rate (OIS) is the rate of the derivative contract on the federal funds rate, and in usual market circumstances is generally below the LIBOR rate. The term LIBOR-OIS spread has the role of evaluating the health of banks, for it mirrors the risk linked with lending to other banks. In times of financial distress, the LIBOR-OIS spread is a fitting indicator of risk premiums as a result of credit and funding liquidity risk (McAndrews et al., 2008; Hui et al., 2011). Alan Greenspan advocates that the LIBOR-OIS spread is an indicator of alarm for bank insolvency, and inflated spread levels reveal struggles in the 
banking industry. Moreover, fluctuations in the LIBOR-OIS spread convey changes in risk premiums (which are caused by a decrease in the rate of default-risk-free asset compared to the rate of the risky asset) rather than in liquidity premiums, which in turn mirror banks' need for liquidity (Thornton, 2009). Besides, the spread includes counterparty-risk premia which originate from the counterparty's ability to pay back an interbank loan. Moreover, the spread contains a significant and time-varying funding liquidity element, as McAndrews et al. (2008) point out. In times of increased uncertainty, such as in financial distress caused by a credit crisis, increase in the risk premium is caused by a decrease in the rate of default-risk-free asset compared to the rate of the risky asset. Such scenario would induce investors to claim their assets from banks, resulting in deposits' flight to safety.

The second variable used in our study is the daily spread between the three-month US and German government bond rate. Any deviation between the US and German government bond rate is mirrored in varying future economic development and interest-rate outlook for the two economies. Fundamentally, different economic and monetary policies between the two biggest economies drive the widening or narrowing of the spread (Cappiello et al., 2006). Correspondingly, US and Euro-zone country specific debt and job market prospects influence US-German bond spread fluctuations (Goldberg and Leonard, 2003). The US and German Government bonds carry no risk (theoretically), as they are considered the two safest assets in the world.

The euro fixed-float OIS swap in which the floating leg is centred on the Euro Over-night Index Average (EONIA) rate, is calculated as the weighted average of all overnight unsecured dealings. Fundamentally, the euro fixedfloat OIS swap is the reflection of the interbank risk premium (Alter and Beyer, 2014). The nominal quantity contracted is in euros, yet only interest cash flows are traded at expiration.

\subsection{Interdependence and causality of short-term money market rates}

Before investigating interdependence and causality among the series, the assumption of stationarity must be assessed and consequently the Augmented Dickey-Fuller (ADF) and Kwiatkowski-Phillips-Schmidt-Shin (KPSS) (1992) tests are implemented. If the series are stationary in their levels, then they are possibly cointegrated and share a common stochastic trend. After determining whether the series have a unit root, interdependencies and causality can be determined. Let $Y_{t}=\left(y_{1 t}, y_{2 t}, y_{3 t}\right)$ denote a $(3 \times 1)$ vector of variables representing the LIBOR-OIS, the EUSWEC and the USGer3M series, with 
$t=1,2, \ldots, T$. Considering that there are three time series in the system, there will be three equations to be solved. The covariates in the three equations are the lagged values of all three time series. Therefore, in the VAR system, the time path of the LIBOR-OIS time series is determined by current and past realisations of the EUSWEC and USGer3M series. Similarly, the time path of the EUSWEC time series is influenced by current and past realisations of the LIBOR-OIS and USGer3M series, and finally the time path of the USGer3M time series is affected by current and past realisations of the EUSWEC and LIBOR-OIS series. The lagged values of the series are weakly exogenous, thus the model does not violate the endogeneity assumption. For every single equation there will be 13 parameters to be estimated. The null hypothesis assumes that the coefficients of the model are jointly zero.

To see the adjustment course of the three time series and to assess how each shock to the forecast error variance feeds back, the IRF is implemented. Due to the fact that the VAR system is under-identified (primitive), at this stage the impulse response functions are only plotted, however one is unable to identify and determine the course and effects of the shocks. These functions are used later in the Cholesky decomposition along with further restrictions to produce the effects of the structural shocks $\left(\epsilon_{L I B O R-O I S_{t}}, \epsilon_{E U S W E C_{t}}\right.$ and $\epsilon_{U S G e r 3 M_{t}}$ ) have on the short-term interbank market - that is to precisely identify leaders and followers in aligning back into equilibrium in the short-term interbank market. At this moment the system introduces an ordering of the variables, and in every single equation one of the time series is exogenous. For example, if $\epsilon_{L I B O R-O I S_{t}}$ shocks do not explain the forecast error variance of the $y_{U S G e r 3 M_{t}}$ spread for all predicted time sequences, then the $y_{U S G e r 3 M_{t}}$ series is said to be exogenous and therefore progresses freely from $\epsilon_{L I B O R-O I S_{t}}$ shocks and from the $y_{L I B O R-O I S_{t}}$ spread. However, if the $\epsilon_{L I B O R-O I S_{t}}$ shocks account for all the forecast error variance in the $y_{U S G e r 3 M_{t}}$ spread for all predicted time sequences, the $y_{U S G e r 3 M_{t}}$ spread would be absolutely endogenous. Knowing the estimated VAR parameters and the elements of the variance/covariance matrix, one can decompose the vector of innovations/shocks into impulse responses, as follows. The restrictions apply to both matrices $\mathbf{A}$ and $\mathbf{B}$.

$$
\mathbf{A} \epsilon_{t}=\mathbf{B} e_{t}
$$

where $\mathbf{A}$ is a lower triangular restricted matrix and $\mathbf{B}$ is a diagonal restricted covariance matrix of structural shocks $\Sigma_{\epsilon}$, which implies that shocks 
to the LIBOR-OIS spread are not correlated with shocks to the EUSWEC or to the USGer3M spreads. $\epsilon_{t}$ are the structural shocks and $e_{t}$ are the VAR innovations.

To find out whether there is causality among the series, the pairwise Granger causality method (1969) is implemented on the VAR estimates. The method tests whether the past values of the LIBOR-OIS spread produce statistically significant information about the EUSWEC spread, for example. The Wald-test (1951), as the basis of the Granger causality method, is a joint hypothesis test that the coefficients on all lags are jointly equal to zero. The VAR residuals are tested for serial correlation using the Durbin-Watson test (1950) and for a unit root.

\subsection{Testing for structural breaks with cointegrated variables}

The Johansen cointegration test (1995) can be implemented solely if the time series have the same level of integration. Johansen's maximum likelihood framework (1988) based on the trace test is used to find the cointegrating vectors and relationships. The lag selection criteria is based on the Akaike Information Criteria (AIC), Schwarz's Bayesian information criterion (BIC), and Hanna-Quinn information criterion (HQIC). An unrestricted cointegration test along with four restricted cointegration tests are implemented, as shown below.

1. Unrestricted trend - this implies that there are quadratic terms in the levels of the LIBOR-OIS, EUSWEC and USGer3M spreads. Moreover, the cointegrating relationships are stationary.

2. Restricted trend - the trends in the spreads are linear, thus the cointegrating relationships are trend stationary.

3. Unrestricted constant - there are linear trends in the differenced series and the relationships are limited to being stationary with a constant mean.

4. Restricted constant - there are no linear trends in the levels of the differenced LIBOR-OIS, USGer3M and EUSWEC series. The cointegrating relationships will have a constant mean, however there won't be trends or constants in the equations.

5. No trend - there are no trends in the relationships. The differences and levels of the series have zero means. 
After the short-run and long-run relationships are established, the GregoryHansen cointegration method (1996) is implemented to test for the presence of structural breaks or regime switches. We're interested to see whether potential long-run equilibrium relationships are disturbed by liquidity crashes observed within the short-term interbank market. We argue that the structural innovations identified by the decomposition of the error terms are essentially liquidity crashes. If the cointegrating vector changes at a single unknown time, the series may return to equilibrium and a linear combination of the series becomes stationary. This test allows for serial correlation among the innovations. A dummy is included in the system of regressions, which identifies a one-time regime shift in the intercept and slope coefficients. The conventional ADF test would not suffice in view of the cointegrating vector shifting at an unknown point in time. The null hypothesis of no cointegration is tested against the alternative hypothesis of cointegration with level shift/structural break/regime shift at a single unknown time. The three models of cointegration with structural breaks are as follows:

A Structural break in the level

$$
y_{1 t}=\mu_{1}+\mu_{2} \phi_{t \tau}+\alpha y_{2 t}+\gamma y_{3 t}+\epsilon_{t}
$$

where $y_{1 t}$ represents the USGer3M spread, $\mu_{1}$ is the intercept previous to a shift, $\mu_{2}$ represents the change in the intercept at the moment of the shift. ${ }^{4} \alpha$ refers to the cointegrating slope coefficient for $y_{2 t}$ (which is the LIBOR-OIS spread) and $\gamma$ represents the cointegrating slope coefficient for $y_{3 t}$ (which represents the EUSWEC rate); $t=1, \ldots, n$ and $\tau \in(0,1)$ is the unidentified parameter and represents the relative timing of the break point; it can only take integer values. The error term satisfies $\epsilon_{t} \sim N\left(0, \sigma^{2}\right)$. The dummy or indicator variable, which has the role of accounting for fluctuations in the constant term and slope coefficients, possesses the following features:

$$
\phi_{t \tau}= \begin{cases}0, & \text { if } t \leq[n \tau] \\ 1, & \text { if } t>[n \tau]\end{cases}
$$

\footnotetext{
${ }^{4}$ The USGer3M bond spread is used as the dependent variable based on our findings in Section 4.2 (see Table 4).
} 
B Level shift with trend

$$
y_{1 t}=\mu_{1}+\mu_{2} \phi_{t \tau}+\beta t+\alpha y_{2 t}+\gamma y_{3 t}+\epsilon_{t}
$$

Beside the change in the intercept, a shift in the slope vector $\beta$ is allowed. $\alpha$ refers to the cointegrating slope coefficient for the LIBOROIS spread and $\gamma$ represents the cointegrating slope coefficient for the EUSWEC spread; $t=1, \ldots, n$ and $\epsilon_{t} \sim N\left(0, \sigma^{2}\right)$.

C Regime shift

$$
\begin{gathered}
y_{1 t}=\mu_{1}+\mu_{2} \phi_{t \tau}+\alpha_{1} y_{2 t}+\alpha_{2} y_{2 t} \phi_{t \tau}+ \\
\gamma_{1} y_{3 t}+\gamma_{2} y_{3 t} \phi_{t \tau}+\epsilon_{t}
\end{gathered}
$$

where $\alpha_{1}$ refers to the cointegrating slope coefficients for the LIBOROIS spread before the regime shift and $\alpha_{2}$ represents the change in slope coefficients. $\gamma_{1}$ refers to the cointegrating slope coefficients for the EUSWEC spread before the regime shift and $\gamma_{2}$ represents the change in the EUSWEC rate after a regime change has occured. $t=1, \ldots, n$ and $\epsilon_{t} \sim N\left(0, \sigma^{2}\right)$.

\section{Empirical results}

The section below provides summary statistics, then Section 4.2 presents the results of the VAR, structural VAR and Granger causality test. Finally, Section 4.3 presents the cointegration test results.

\subsection{Summary statistics}

There are 3651 observations for each of the three variables. Owing to the fact that the data changes persistently, it is hard to find a measure of central tendency for the entire length of the analysed time interval. Table 1 presents the summary statistics of the LIBOR-OIS, EUSWEC and USGer3M time series. The point estimate of the LIBOR-OIS spread is 25.56, with minimum and maximum values ranging between 1.91 - 364.42. The variation around the mean is high with a value of 34.93. The mean and standard deviation for 
the EUSWEC and USGer3M spreads are close to zero and one, respectively; the minimum and maximum values are in much narrower interval. All three time series are skewed to the right and they are peaked around the mean, with the LIBOR-OIS spread showing an amplified excess kurtosis. The plots of the daily time series (see Figure 1) show stochastic trends, that is they increase and decrease over time. The top panel of Figure 1 is particularly interesting, for it depicts the financial crisis of 2007-08. A closer inspection of panel two and three reveal a similar behaviour.
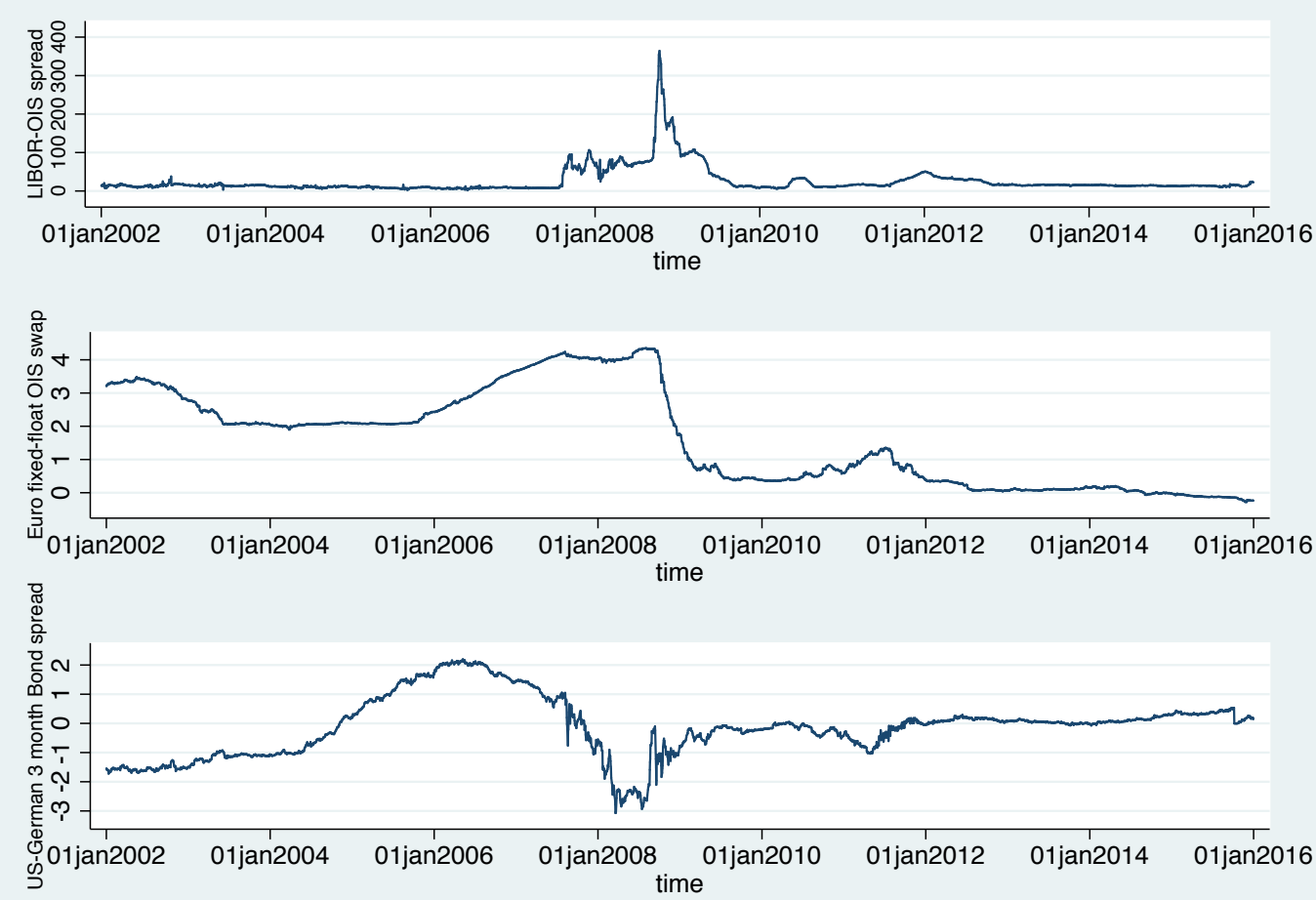

Figure 1: Behaviour of the LIBOR-OIS, EUSWEC and USGer3M time series for the period 1st January 2002 to 30th December 2015.

The ADF test confirms (see Table 1) that the variables contain a unit root, and therefore are stationary in their levels. The KPSS test for stationarity (Kwiatkowski et al., 1992) confirms that the spreads are not trend stationary. At this time, it is essential to modify the time series to permit a reliable evaluation of the relationships among the spreads. As data in the lower half of Table 1 shows, the mean values of all three series get close to 
Table 1: Summary statistics of the LIBOR-OIS, USGer3M and EUSWEC spreads.

\begin{tabular}{lccccccc}
\hline \hline \multicolumn{1}{c}{ Variable } & Mean & Std. Dev. & Min. & Max. & Skewness & Kurtosis & ADF (p values) \\
\hline USLIBOIS & 25.560 & 34.93 & 1.91 & 364.42 & 4.52 & 30.75 & $-2.60(0.09)$ \\
USGer3M & -0.121 & 1.00 & -3.07 & 2.20 & 0.07 & 3.13 & $-1.37(0.60)$ \\
EUSWEC & 1.623 & 1.44 & -0.28 & 4.35 & 0.37 & 1.74 & $-0.73(0.84)$ \\
diff. USLIBOIS & 0.002 & 2.85 & -39.65 & 37.55 & 0.38 & 71.35 & $-54.28(0.00)$ \\
diff. USGer3M & 0.0004 & 0.06 & -0.97 & 0.88 & -0.66 & 53.66 & $-59.00(0.00)$ \\
diff. EUSWEC & -0.0009 & 0.02 & -0.29 & 0.19 & -2.89 & 53.68 & $-57.17(0.00)$ \\
\hline
\end{tabular}

zero. The KPSS test corroborates the ADF test results, thus first differencing the time series produces a mean-reverting process.

\subsection{VAR, Structural VAR and Granger causality}

At the moment, there is no information on which of the three time series is exogenous. All three variables are treated symmetrically in the VAR system. The AIC, HQIC and Schwarz's Bayesian information criterion suggest that the optimal lag is four. The configuration of the VAR(4) system contains impulse responses (or feedback), as a result that the LIBOR-OIS, the EUSWEC and the USGer3M spreads and their lags are permitted to interact with and influence each other.

The VAR(4) results are presented in Table 2. The null hypothesis that jointly the coefficients are zero is rejected. It can be concluded that the LIBOR-OIS spread is a good predictor of changes in the EUSWEC spread. At $5 \%$ significance level, for every unit increase in the first lagged LIBOR-OIS spread a 0.0003 unit increase in the EUSWEC spread is predicted. Similarly, the USGer3M spread is a good predictor of changes in the EUSWEC rate. For every unit increase in the fourth lag of the USGer3M spread a 0.0118 unit decrease in the EUSWEC spread is predicted. Furthermore, for every unit increase in the first lagged EUSWEC spread a -9.3069 unit decrease in the LIBOR-OIS spread is predicted. It seems that various lags of some of the variables have an ex-post effect on the present observations of the other two. This might be accredited to the fact that a single shock may last several periods as a result of autoregressive attributes of the time series. Another explanation is that a shock's effect is not experienced in its full force instantaneously, but after some time has lapsed. For example, for every unit increase in the forth lagged EUSWEC rate a 0.0967 unit increase in the USGer3M spread is predicted. 
Table 2: VAR(4) estimates for the LIBOR-OIS, EUSWEC and USGer3M spreads.

\begin{tabular}{lccc}
\hline Main & D.USLIBOIS & D.USGer3M & D.EUSWEC \\
\hline \hline LD.USLIBOIS & $0.06^{* * *}$ & $0.0009^{*}$ & $0.0003^{* * *}$ \\
& $(3.52)$ & $(2.59)$ & $(2.93)$ \\
L2D.USLIBOIS & $0.12^{* * *}$ & -0.0002 & 0.0001 \\
& $(7.50)$ & $(-0.76)$ & $(1.42)$ \\
L3D.USLIBOIS & $0.14^{* * *}$ & $-0.0009^{*}$ & $0.0003^{* * *}$ \\
& $(8.40)$ & $(-2.51)$ & $(-3.18)$ \\
L4D.USLIBOIS & $0.06^{* * *}$ & 0.0004 & 0.00 \\
& $(3.95)$ & $(1.25)$ & $(-0.38)$ \\
LD.EUSWEC & $-9.31^{* * *}$ & $0.38^{* * *}$ & $0.05^{* * *}$ \\
& $(-3.73)$ & $(6.53)$ & $(2.79)$ \\
L2D.EUSWEC & -24.80 & -0.11 & $0.16^{* * *}$ \\
& $(-9.90)$ & $(-1.95)$ & $(9.40)$ \\
L3D.EUSWEC & $8.99^{* * *}$ & 0.03 & -0.005 \\
& $(3.55)$ & $(0.52)$ & $(-0.30)$ \\
L4D.EUSWEC & $12.36^{* * *}$ & $0.10^{* *}$ & $0.13^{* * *}$ \\
& $(4.89)$ & $(1.65)$ & $(7.85)$ \\
LD.USGer3M & $-11.50^{* * *}$ & 0.03 & $-0.01^{* * *}$ \\
& $(-16.16)$ & $(1.67)$ & $(-2.78)$ \\
L2D.USGer3M & 0.96 & 0.02 & 0.00 \\
& $(1.30)$ & $(1.21)$ & $(0.02)$ \\
L3D.USGer3M & 1.28 & 0.002 & $-0.02^{* * *}$ \\
& $(1.74)$ & $(0.10)$ & $(-4.58)$ \\
L4D.USGer3M & $3.38^{* * *}$ & $-0.09^{* * *}$ & $-0.01^{*}$ \\
& $(4.60)$ & $(-5.42)$ & $(-2.05)$ \\
\hline
\end{tabular}

${ }^{* * *} \mathrm{p}<0.05,{ }^{* *} \mathrm{p}<0.1,{ }^{*} \mathrm{p}<0.01$ 


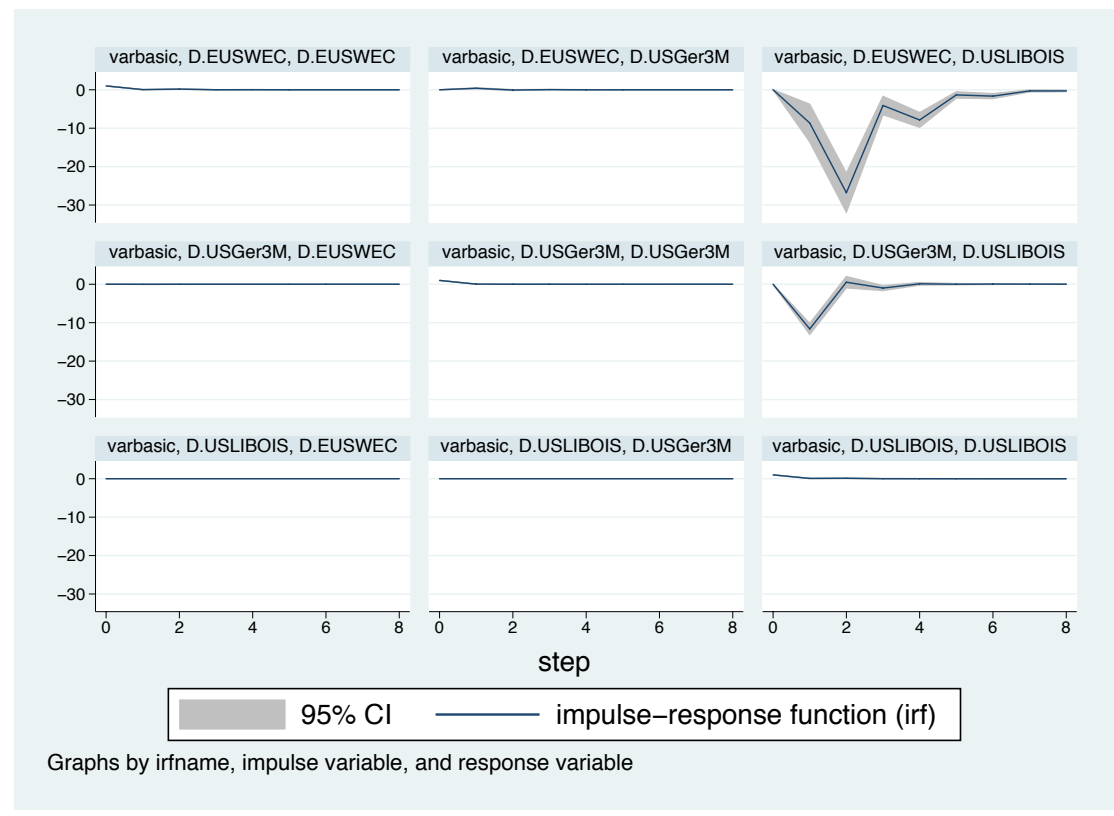

Figure 2: Impulse response function of the coefficients after fitting the VAR(4).

The residuals of the regressions are stationary as supported by the ADF and KPSS tests. Moreover, the residuals are not correlated as confirmed by the Durbin-Watson test. The stability condition of the VAR(4) parameters is satisfied as all eigenvalues lie within the unit circle; thus, the system is stationary and consequently the impulse response functions are interpretable. As it can be seen from Figure 2, shocks are persistent, however with time they die away. Both the USGer3M and EUSWEC spreads are affected by shocks induced by the LIBOR-OIS spread. If after some shocks the equilibrium errors return to zero, a long-run equilibrium among the LIBOR-OIS, USGer3M and EUSWEC spreads exists.

The Granger causality test coefficients are presented in Table 3. The null hypothesis that the EUSWEC does not Granger-cause LIBOR-OIS can be rejected; similarly, the null hypothesis that the coefficients on the four lags of the USGer3M in the equation for LIBOR-OIS are zero can be rejected. Last, the null hypothesis that the USGer3M does not Granger-cause the LIBOR-OIS can be rejected. For the third equation, the coefficients of both endogenous variables are not jointly zero. Therefore, the null hypothesis that the EUSWEC and USGer3M series do not Granger-cause the LIBOR-OIS 
can be rejected.

Table 3: Granger causality Wald test coefficients.

\begin{tabular}{ccccc}
\hline \hline Equation & Excluded from equation & chi2 & df & Prob. chi2 \\
\hline \hline D_USLIBOIS & D.EUSWEC & 284.79 & 4 & 0.000 \\
D_USLIBOIS & D_USGer3M & 132.81 & 4 & 0.000 \\
D_USLIBOIS & All & 466.98 & 8 & 0.000 \\
\hline D_EUSWEC & D.USLIBOIS & 18.65 & 4 & 0.001 \\
D_EUSWEC & D.USGer3M & 29.542 & 4 & 0.000 \\
D_EUSWEC & All & 55.165 & 8 & 0.000 \\
\hline D_USGer3M & D.USLIBOIS & 13.893 & 4 & 0.008 \\
D_USGer3M & D.EUSWEC & 50.349 & 4 & 0.000 \\
D_USGer3M & All & 65.292 & 8 & 0.000 \\
\hline
\end{tabular}

The Cholesky decomposition is represented by the lower triangular $\mathbf{A}$ matrix and $\mathbf{B}$, a diagonal matrix, with the estimated values displayed in Equations 6 and 7 . Since there are three variables, the number of restrictions is $\left(3^{2}-3\right) / 2=3$. In the first equation, the restrictions imply that the LIBOR-OIS equation does not contain contemporaneous EUSWEC and USGer3M series; more precisely, it means that the LIBOR-OIS spread is not contemporaneously affected by shocks originating from the EUSWEC and USGer3M series correspondingly. In the second equation of matrix $\mathbf{A}$, the EUSWEC spread responds to changes in the LIBOR-OIS spread, but not to contemporaneous changes in the USGer3M spread. In the third equation, the USGer3M spread responds to contemporaneous changes in the LIBOR-OIS and EUSWEC spread correspondingly:

$$
\mathbf{A}=\left(\begin{array}{ccc}
1 & 0 & 0 \\
-0.0002 & 1 & 0 \\
0.0013 & -0.0969 & 1
\end{array}\right)
$$

A zero restriction on the coefficients of the established variables is imposed. The matrix below displays the values representing the speed of adjustment to liquidity shocks. If the short-term interbank market is affected by a liquidity shock, the LIBOR-OIS spread is a leader in moving back into equilibrium, whereas the currency swap and the US-German bond spreads are followers. 


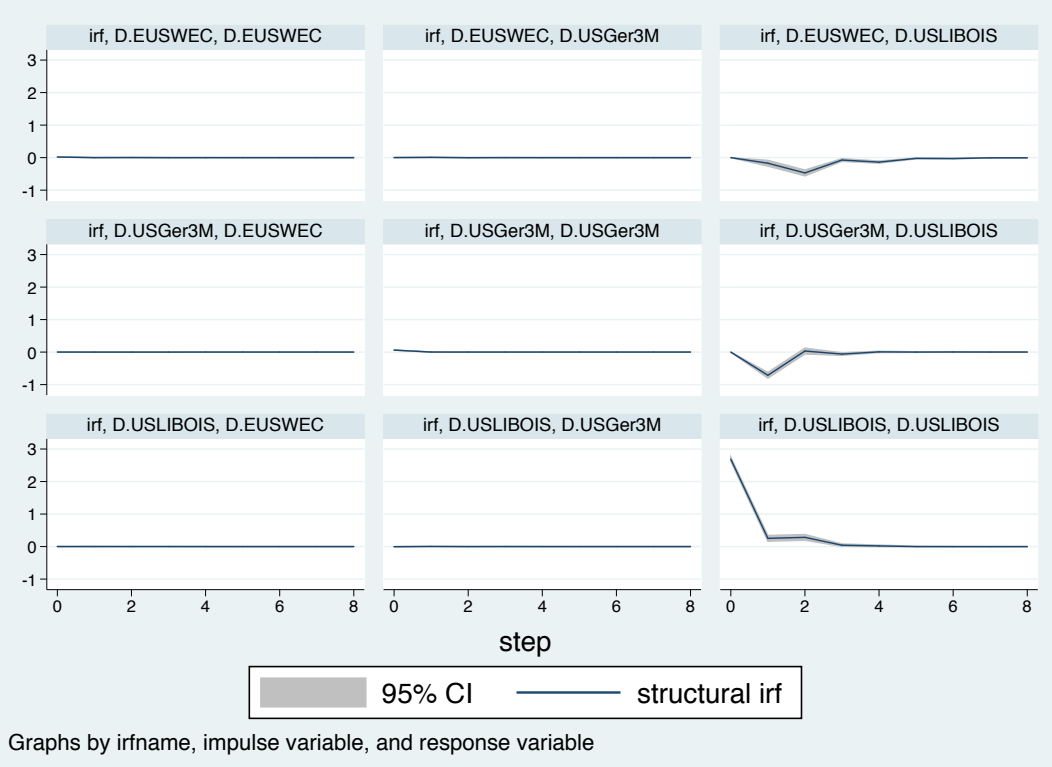

Figure 3: Plot of the structural impulse responses.

$$
\mathbf{B}=\left(\begin{array}{ccc}
2.686 & 0 & 0 \\
0 & 0.0176 & 0 \\
0 & 0 & 0.0613
\end{array}\right)
$$

The results with the values of the Cholesky decomposition are presented in Table 4. A 1\% increase in the current LIBOR-OIS spread affects the current EUSWEC spread by $0.0005 \%$, and $1 \%$ increase in the current LIBOROIS spread affects the euro fixed-float OIS swap by $0.00171 \%$ and the USGer3M spread by $-0.00345 \%$.

Table 4: Estimates of the Cholesky decomposition of the covariance matrix of residuals.

\begin{tabular}{lccc}
\hline \multicolumn{1}{c}{ Variable } & USLIBOIS & EUSWEC & USGer3M \\
\hline LIBOR-OIS & 2.69 & 0 & 0 \\
EUSWEC & 0.00054 & 0.0176 & 0 \\
USGer3M & -0.00345 & 0.00171 & 0.0613 \\
\hline
\end{tabular}

The forecast error variance decomposition calculated the fraction of the 
movement in a sequence owing to its individual shocks reacting against shocks of the other two time series. The results suggest that the euro fixed-float OIS swap rate rises as the LIBOR-OIS spread increases. The US-German bond spread is positively related to the currency euro fixed-float OIS swap rate and negatively related to the LIBOR-OIS rate. The impulse response functions presented in Figure 2 are consistent with these findings.

\subsection{Long-run relationships within the interbank market and structural breaks}

The results presented in Table 5 reveal that there are cointegrating relationships for the constant case, the restricted trend case, for the restricted constant case and for the case when there is no trend nor a constant in the equation. At $r=1$, the trace statistic is below the $5 \%$ critical values for all the three cases. Therefore, the null hypothesis that there is one cointegrating relationship in the system of equations cannot be rejected. The next step is to fit a VECM for the identified cases (equation with constant, equation with restricted trend, equation with restricted constant and no trend nor a constant in the equation) and estimate the long-run and short-run coefficients. Vector error correction implies that a departure from equilibrium in one period is corrected in the subsequent period; or more precisely, deviations from the long-run equilibrium condition are introduced into the short-time dynamics (Johansen, 1995). Basically, the VECM is formulated as the response of the LIBOR-OIS and EUSWEC shocks to the USGer3M spreads, and implies that the cointegrating vector reduces the series to stationarity.

The dependent variable is the three-month US-German bond spread based on the Cholesky decomposition result, where the LIBOR-OIS spread became the leader, while the EUSWEC and USGer3M spreads were followers in transmitting liquidity shocks. The significant error correction coefficients $(\boldsymbol{\alpha})$ and long-run cointegrating parameters are presented in Table 6. The lagged terms' significant coefficients signal short-run causality in the equilibrium model, while showing the speed of adjusting back to the equilibrium level. All error correction terms (or adjustment coefficients) are significant at $10 \%$ critical value. However, the estimated $\boldsymbol{\alpha}$ 's are meaningful when the first error correction coefficient in the model takes a negative value. The restricted trend equation does not fit, however in the unrestricted constant, restricted constant and no trend no constant cases the models fit well. For these three cases one can argue that there is a long-term causality running in both directions between the USGer3M, LIBOR-OIS and EUSWEC spreads. For example, when the average three-month US-German bond spread is too high 
Table 5: Rank test for the eq. with constant (Panel A), eq. with trend (Panel B), equation with restricted constant (Panel C), eq. with restricted trend (Panel D) and eq. with no constant and no trend (Panel E), maxlag(4).

\begin{tabular}{lccccc}
\hline \hline \multicolumn{1}{c}{ Rank } & Param & LL & eigenvalue & trace stat. & 5\% crit. val. \\
\hline Panel A & & & & & \\
\hline 0 & 12 & 5663.80 &. & 310.64 & 29.68 \\
1 & 17 & 5813.78 & 0.078 & $10.70^{*}$ & 15.41 \\
2 & 20 & 5816.54 & 0.0015 & 5.17 & 3.76 \\
3 & 21 & 5819.13 & 0.0014 & & \\
\hline \hline Panel B & & & & & \\
\hline 0 & 15 & 5664.04 &. & 354.38 & 34.55 \\
1 & 20 & 5831.98 & 0.087 & 18.50 & 18.17 \\
2 & 23 & 5838.78 & 0.0037 & 4.91 & 3.74 \\
3 & 24 & 5841.23 & 0.0013 & & \\
\hline \hline Panel C & & & & & \\
\hline 0 & 9 & 5658.90 &. & 320.45 & 34.91 \\
1 & 15 & 5813.45 & 0.081 & $11.35 *$ & 19.96 \\
2 & 19 & 5816.53 & 0.0016 & 5.18 & 9.42 \\
3 & 21 & 5819.13 & 0.0014 & & \\
\hline \hline Panel D & & & & & \\
\hline 0 & 12 & 5663.80 &. & 354.86 & 42.44 \\
1 & 18 & 5831.81 & 0.087 & $18.84^{*}$ & 25.32 \\
2 & 22 & 5838.60 & 0.0037 & 5.26 & 12.25 \\
3 & 24 & 5841.23 & 0.0014 & & \\
\hline \hline Panel E & & & & & \\
\hline 0 & 9 & 5658.90 &. & 308.55 & 24.31 \\
1 & 14 & 5808.57 & 0.078 & $9.21^{*}$ & 12.53 \\
2 & 17 & 5811.59 & 0.0016 & 3.16 & 3.84 \\
3 & 18 & 5813.18 & 0.0008 & & \\
\hline
\end{tabular}


Table 6: Estimates of the short-run VECM coefficients ( $\boldsymbol{\alpha}$ 's) and long-run cointegrating parameters $(\boldsymbol{\beta}$ 's).

\begin{tabular}{lcc}
\hline \hline \multicolumn{1}{c}{ Equation } & $\boldsymbol{\alpha}$ & $\boldsymbol{\beta}$ \\
\hline \hline Unrestricted Constant & $(-0.0002,0.020,0.0002)$ & $(1,-0.53,3.24)$ \\
Restricted Trend & $(0.0003,-0.0234,-0.0002)$ & $(1,0.599,-9.124)$ \\
Restricted Constant & $(-0.0002,0.020,0.0002)$ & $(1,-0.516,3.157)$ \\
No Trend and Constant & $(-0.0004,0.030,0.0003)$ & $(1,-0.321,3.061)$ \\
\hline
\end{tabular}

(with the coeff. value of -0.0002), this will decrease back to the LIBOR-OIS spread and euro fixed-float OIS swap level. In the no trend no constant case the coefficient on the LIBOR-OIS spread is 0.030 . This means that when the average USGer3M spread is too high, the LIBOR-OIS spread level rapidly adjusts (increases in this case) towards the USGer3M level, while at the same time the USGer3M spread adjusts as well.

For all four equations, the estimated $\boldsymbol{\beta}$ 's, which represent the parameters of the cointegrating relationships, are significant at $5 \%$ critical level. For the unrestricted constant case, restricted constant case and for the no trend no constant case, the long-run cointegrating equations are as follows:

$$
\begin{gathered}
y_{U S G e r 3 M}=3.24 y_{E U S W E C}-0.53 y_{L I B O R-O I S} \\
y_{U S G e r 3 M}=3.157 y_{E U S W E C}-0.516 y_{L I B O R-O I S} \\
y_{U S G e r 3 M}=3.61 y_{E U S W E C}-0.321 y_{L I B O R-O I S}
\end{gathered}
$$

Next, the specification of the three models that proved to fit well is tested. A graph of the levels gives a guidance as to whether the estimated cointegrating equations are stationary. As it can be seen in Figure 4 (which represents the unrestricted constant, restricted constant and no trend and no constant 


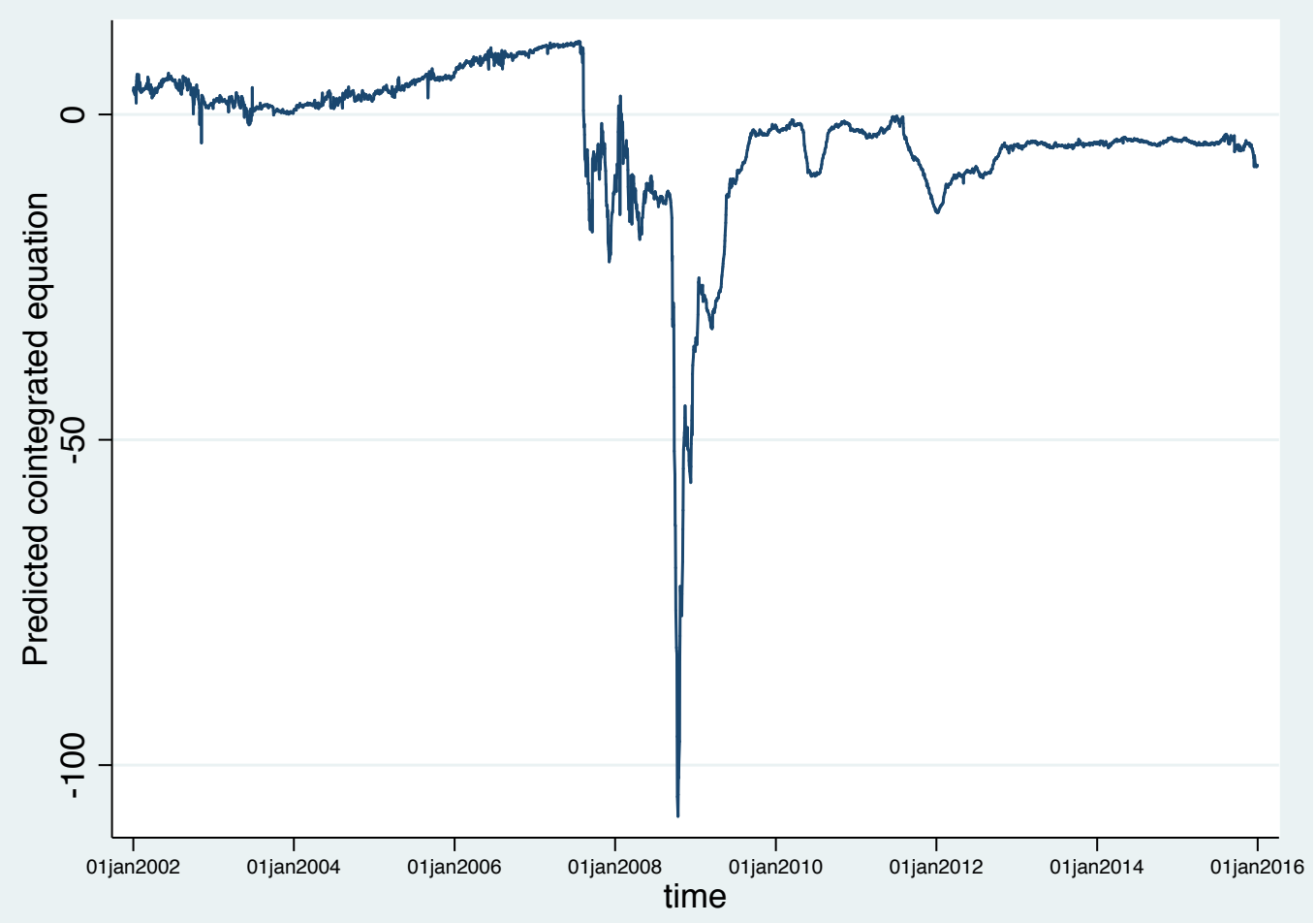

Figure 4: Predicted cointegrating equation versus time for the unrestricted constant, restricted constant and no trend and no constant cases.

cases), there is a major and long-lasting break in the long-run relationship which starts at the end of 2007. The timing corresponds to the start of the financial crisis of 2007-08. Moreover, the graph tells us that the break lasted approximately until the end of 2009.

The stability of the estimates are checked and all eigenvalues lie within the unit circle, proving that the number of cointegrating equations were successfully and correctly selected. The obtained cointegrated relationships are used to generate forecast, and subsequently compare the variances of the impulse responses obtained from the $\operatorname{VAR}(4)$ with the dynamic error forecasts obtained from the VECM. Significant distinctions are revealed. Earlier, Figure 2 showed that the error forecasts from the first differenced stationary VAR(4) model converge to zero with time, whereas the dynamic error forecasts in Figure 5 deviate towards infinity. These findings strongly indicate the presence of at least one structural break in the time series. If structural 

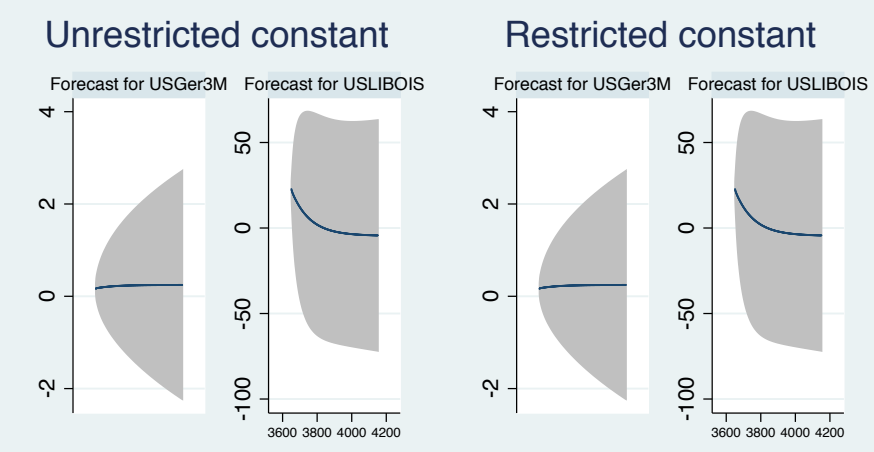

No constant no trend
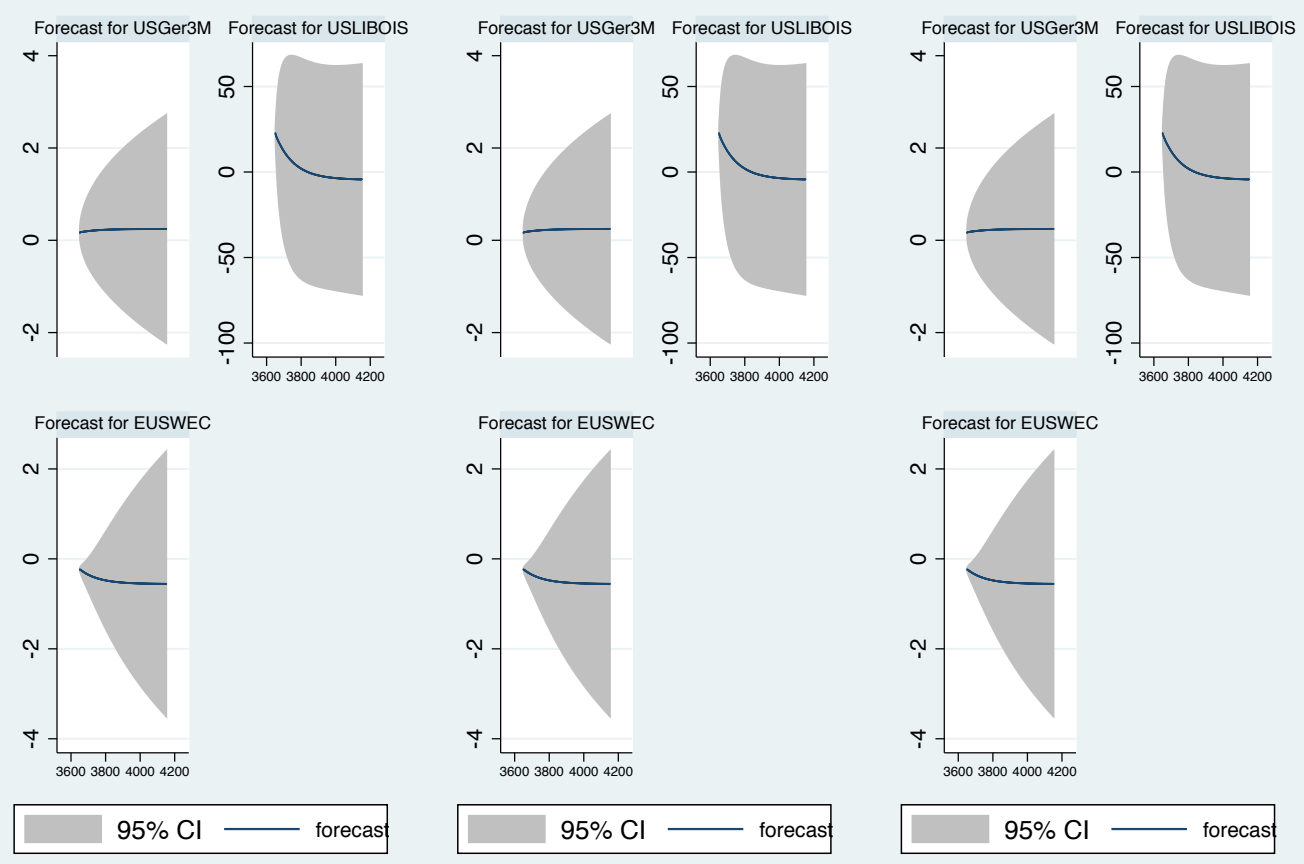

Forecast for EUSWEC

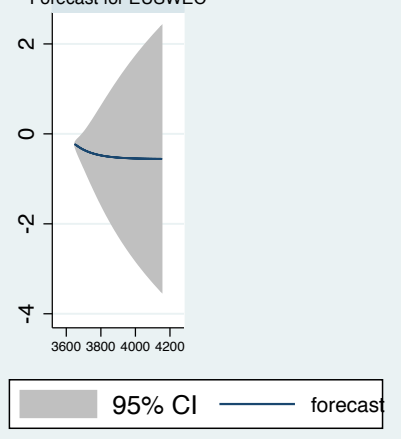

Figure 5: Dynamic 500 days forecasts of the levels for the unrestricted constant, restricted constant and no trend no constant cases. The x axes run from observations 3591 to 4200 , which correspond to dates 1st of January 2016 to May 2017. 
Table 7: Results of the Gregory-Hansen tests of structural break in the level (A), level shift with trend (B) and regime shift $(\mathrm{C})$.

\begin{tabular}{lccccc}
\hline \hline & Test Stat. & Break & 1\% crit. val. & $\mathbf{5 \%}$ crit. val. & 10\% crit. val. \\
\hline (A) & & & & & \\
ADF & -3.64 & 719 & -5.44 & -4.92 & -4.69 \\
Zt & -3.05 & 723 & -5.44 & -4.92 & -4.69 \\
Za & -19.41 & 723 & -57.01 & -46.98 & -42.49 \\
\hline (B) & & & & & \\
ADF & -7.56 & 1593 & -6.45 & -5.96 & -5.72 \\
Zt & -7.26 & 1761 & -6.45 & -5.96 & -5.72 \\
Za & -115.06 & 1761 & -79.65 & -68.43 & -63.10 \\
\hline C) & & & & & \\
ADF & -6.27 & 1469 & -5.97 & -5.50 & -5.23 \\
Zt & -6.86 & 1463 & -5.97 & -5.50 & -5.23 \\
Za & -205.69 & 1463 & -68.21 & -58.33 & -52.85 \\
\hline
\end{tabular}

changes occur at a single time $t$, these will have an everlasting affect on the behaviour of the time series which is a characteristic of unit root processes.

Table 7 reports the Gregory-Hansen test (1996) results which reveal whether the established equilibrium relationships are disturbed by a onetime structural break or regime change. $t$ spans from 1st January 2002 to 31 th December 2015, and $t=1,2, \ldots, 3651$. At $5 \%$ significance, the test for structural break in the level (A) does not confirm (for all three test statistics: ADF, the Phillips $Z_{\alpha}$ and $Z_{t}$ test statistics) that there is a shift. Therefore, the null hypothesis of no cointegration with shift in the level cannot be rejected. For the level shift with trend test (B), at 5\% significance, all of the tests statistics identify a structural change at time $t=1593, t=1761$ and $t=1761$, and this corresponds to 18th October 2007 and 30th September 2008. Similarly, for the regime shift test (C), all of the three test statistics are significant at $5 \%$ significance level, therefore the null hypothesis of no cointegration with regime change can be rejected. The change dates are at $t=1469, t=1463$ and $t=1463$, and correspond to the 9th of August 2007 and the 17th of August 2007. These dates are important considering the fact that the first signs of a financial crisis looming in the interbank market appeared in August 2007. 


\section{Conclusions}

From a policy perspective it is imperative to be able to forecast interest rate movements caused by liquidity shocks within the interbank market. Our study provides an insight into fundamental money market rates behaviour by uncovering significant dependencies, inter-relationships and at the same time tracing the path of structural innovations. The LIBOR-OIS, the euro fixedfloat OIS swap rate and the US-German bond spread move in a synchronised fashion and this ultimately has implications for policy-makers and market players alike. Impulse responses suggest that shocks affecting the interbank market are meaningful and persistent, such that the USGer3M and EUSWEC spreads are affected by shocks induced by the LIBOR-OIS spread indicating endogenous responses and spillover effects within the short-term interbank market. The variance decomposition calculates the fraction of the movement in a sequence, owing to its individual shocks reacting against shocks of the other two time series. If a liquidity shock affects the short-term interbank market, the LIBOR-OIS spread is the leader, whereas the EUSWEC and USGer3M spreads are followers in aligning back into equilibrium. Dynamic forecasts indicated the presence of at least one structural break; thus, the magnitude of shocks translating into structural breaks is large and infrequent, and consequently the long-run relationships break down temporarily. The structural break observed in the short-term interbank market on the 9th of August 2007 coincides with BNP Paribas banks' announcement that some of its mortgage backed assets could not be valued. Uncertainty increased and this was owed to the imminent liquidity shortage developed in money market, which essentially was the start of the Financial crisis of 2007-08. Therefore, this study shows evidence of early warning signals in the like of structural liquidity shocks which can be detected in advance of financial crises.

\section{References}

Abrantes-Metz, R. M., Kraten, M., Metz, A. D., and Seow, G. S. (2012). Libor manipulation? Journal of Banking and Finance, 36(1):136-150.

Allen, F., Babus, A., and Carletti, E. (2009). Financial crises: Theory and evidence. Annual Review of Financial Economics, 1(1):97-116.

Allen, F., Babus, A., and Carletti, E. (2010). Financial connections and systemic risk. Technical report, National Bureau of Economic Research. 
Allen, F. and Gale, D. (2000). Financial contagion. Journal of Political Economy, 108(1):1-33.

Alter, A. and Beyer, A. (2014). The dynamics of spillover effects during the European sovereign debt turmoil. Journal of Banking and Finance, 42:134-153.

Baba, N., Packer, F., and Nagano, T. (2008). The spillover of money market turbulence to FX swap and cross-currency swap markets. BIS Quarterly Review, March:73-86.

BIS (2013). Towards better reference rate practices: a central bank perspective. Technical report, Bank for International Settlements.

Brunnermeier, M. K. and Oehmke, M. (2012). Bubbles, financial crises, and systemic risk. Technical report, National Bureau of Economic Research.

Cappiello, L., Engle, R. F., and Sheppard, K. (2006). Asymmetric dynamics in the correlations of global equity and bond returns. Journal of Financial Econometrics, 4(4):537-572.

Chau, F. and Deesomsak, R. (2014). Does linkage fuel the fire? The transmission of financial stress across the markets. International Review of Financial Analysis, 36:57-70.

Cifuentes, R., Ferrucci, G., and Shin, H. S. (2005). Liquidity risk and contagion. Journal of the European Economic Association, 3(2-3):556-566.

Daníelsson, J. (2011). Financial Risk Forecasting: The Theory and Practice of Forecasting Market Risk with Implementation in $R$ and Matlab. The Wiley Finance Series. Wiley.

Daníelsson, J. and Saltoğlu, B. (2003). Anatomy of a market crash: A market microstructure analysis of the Turkish overnight liquidity crisis. In EFA 2003 Annual Conference Paper.

Durbin, J. and Watson, G. S. (1950). Testing for serial correlation in least squares regression: I. Biometrika, 37:409-428.

Eichengreen, B., Rose, A. K., and Wyplosz, C. (1996). Contagious currency crises. Working Paper 5681, National Bureau of Economic Research. 
Eisenberg, L. and Noe, T. H. (2001). Systemic risk in financial systems. Management Science, 47(2):236-249.

Fouquau, J. and Spieser, P. K. (2015). Statistical evidence about LIBOR manipulation: A Sherlock Holmes investigation. Journal of Banking and Finance, 50:632-643.

Frank, N., González-Hermosillo, B., and Hesse, H. (2008). Transmission of liquidity shocks: Evidence from the 2007 subprime crisis. International Monetary Fund Working Paper, 08(200).

Freixas, X., Parigi, B. M., and Rochet, J.-C. (2000). Systemic risk, interbank relations, and liquidity provision by the central bank. Journal of Money, Credit and Banking, 32(3):611-638.

Furfine, C. H. (2003). Interbank exposures: Quantifying the risk of contagion. Journal of Money, Credit and Banking, 35(1):111-128.

Gai, P. and Kapadia, S. (2010). Contagion in financial networks. Proceedings of the Royal Society: Mathematical, Physical and Engineering Science.

Goldberg, L. S. and Leonard, D. (2003). What moves sovereign bond markets? The effects of economic news on US and German yields. Current Issues in Economics and Finance, 9(9).

Gorton, G. and Metrick, A. (2012). Securitized banking and the run on repo. Journal of Financial Economics, 104(3):425 - 451.

Granger, C. W. J. (1969). Investigating Causal Relations by Econometric Models and Cross-Spectral Methods. Econometrica, 37(3):424-38.

Gregory, A. W. and Hansen, B. E. (1996). Residual-based tests for cointegration in models with regime shifts. Journal of Econometrics, 70(1):99 126.

Guo, F., Chen, C. R., and Huang, Y. S. (2011). Markets contagion during financial crisis: A regime-switching approach. International Review of Economics and Finance, 20(1):95 - 109.

Gyntelberg, J. and Wooldridge, P. D. (2008). Interbank rate fixings during the recent turmoil. BIS Quarterly Review. 
Hartmann, P., Manna, M., and Manzanares, A. (2001). The microstructure of the euro money market. Journal of International Money and Finance, 20(6):895-948.

He, Z. and Krishnamurthy, A. (2011). A model of capital and crises. The Review of Economic Studies, pages 1-43.

Hou, D. and Skeie, D. R. (2014). Libor: origins, economics, crisis, scandal, and reform. Technical Report 667, Federal Reserve Bank of New York.

Hui, C.-H., Genberg, H., and Chung, T.-K. (2011). Funding liquidity risk and deviations from interest-rate parity during the Financial Crisis of 20072009. International Journal of Finance and Economics, 16(4):307-323.

Johansen, S. (1988). Statistical analysis of cointegration vectors. Journal of Economic Dynamics and Control, 12(2-3):231-254.

Johansen, S. (1995). Identifying restrictions of linear equations with applications to simultaneous equations and cointegration. Journal of Econometrics, 69(1):111 - 132 .

Kaminsky, G. L. and Reinhart, C. M. (2000). On crises, contagion, and confusion. Journal of International Economics, 51(1):145 - 168.

Kodres, L. E. and Pritsker, M. (2002). A rational expectations model of financial contagion. The Journal of Finance, 57(2):769-799.

Kwiatkowski, D., Phillips, P. C., Schmidt, P., and Shin, Y. (1992). Testing the null hypothesis of stationarity against the alternative of a unit root: How sure are we that economic time series have a unit root? Journal of Econometrics, 54(1):159-178.

Mackenzie, M. and Tett, G. (2008). Libor remarks fail to put unease to rest. Financial Times.

Makarov, I. and Plantin, G. (2013). Equilibrium subprime lending. The Journal of Finance, 68(3):849-879.

McAndrews, J., Sarkar, A., and Wang, Z. (2008). The effect of the term auction facility on the London inter-bank offered rate. Federal Reserve Bank of New York. Staff Report. 
Michaud, F.-L. and Upper, C. (2008). What drives interbank rates? Evidence from the Libor panel. BIS Quarterly Review, March.

Mistrulli, P. E. (2011). Assessing financial contagion in the interbank market: Maximum entropy versus observed interbank lending patterns. Journal of Banking and Finance, 35(5):1114 - 1127.

Mollenkamp, C. and Whitehouse, M. (2008). Study Casts Doubt on Key Rate. The Wall Street Journal.

Nier, E., Yang, J., Yorulmazer, T., and Alentorn, A. (2007). Network models and financial stability. Journal of Economic Dynamics and Control, 31(6):2033-2060.

Schwarz, K. (2014). Mind the gap: Disentangling credit and liquidity in risk spreads. Available at: http://dx.doi.org/10.2139/ssrn.1486240.

Sengupta, R. and Tam, Y. M. (2008). The LIBOR-OIS spread as a summary indicator. Economic Synopses, 2008(2008-10-15).

Shin, H. S. (2008). Risk and liquidity in a system context. Journal of Financial Intermediation, 17(3):315-329.

Sims, C. A. (1980). Macroeconomics and reality. Econometrica, 48(1):1-48.

Smimou, K. and Khallouli, W. (2016). On the intensity of liquidity spillovers in the Eurozone. International Review of Financial Analysis. In Press, Corrected proof.

Thornton, D. L. (2009). What the LIBOR-OIS spread says. Available: https://research.stlouisfed.org/publications/es/09/ES0924.pdf.

Upper, C. (2011). Simulation methods to assess the danger of contagion in interbank markets. Journal of Financial Stability, 7(3):111 - 125.

Upper, C. and Worms, A. (2004). Estimating bilateral exposures in the German interbank market: Is there a danger of contagion? European Economic Review, 48(4):827 - 849.

Wald, A. (1951). On some systems of equations of mathematical economics. Econometrica: Journal of the Econometric Society, 19(4):368-403. 
Wiseman, J. D. (2008). Some confusion over Libor levels. Financial Times.

Zhou, W. and He, J. (2012). A novel financial risk contagion model based on the MGARCH process and its parameter estimation. African Journal of Business Management, 6(19):6014-6018. 